\title{
Factors That Influence Career Decisions in Canada's Nurses
}

Sheri Price, RN, PhD

Assistant Professor, Dalhousie University, School of Nursing

Halifax, NS

Linda McGillis Hall, RN, PhD

Kathleen Russell Distinguished Professor

Lawrence S. Bloomberg Faculty of Nursing, University of Toronto

Toronto, ON

Michelle Lalonde, RN, MN

Lecturer, Lawrence S. Bloomberg Faculty of Nursing, University of Toronto

Toronto, ON

Gavin Andrews, $\mathrm{PhD}$

Professor, Department of Health, Aging \& Society, McMaster University

Hamilton, ON

Alexandra Harris, RN, MN, MBA

Graduate Student, Lawrence S. Bloomberg Faculty of Nursing, University of Toronto Toronto, ON

Sandra MacDonald-Rencz, RN, MEd

Nursing Executive Advisor, Strategic Policy Branch, Health Canada

Ottawa, ON 


\begin{abstract}
Understanding the experiences of nurses who have moved between the provinces and territories $(P / T)$ in Canada for work provides insight into the role of professional socialization in career decision-making. This paper analyzes some of the qualitative data arising from a survey of nurses from across Canada. The findings provide insight into nurses' professional socialization and demonstrate that early perceptions and expectations of nursing practice can influence future career decisions such as mobility and intent to remain. Participants described how "caring" and direct patient contact were central to their choice of nursing and career satisfaction. As the data reveal, nursing is also regarded as a career that enables mobility to accommodate both family considerations and professional development opportunities. The findings highlight the need for professional socialization strategies and supports that motivate Canadian nurses to continue practising within the profession and the country.
\end{abstract}

\title{
Background
}

For over a decade, there has been considerable focus on the nursing shortage both nationally and internationally (CNA 2009; WHO 2006). Besides recruitment, planning in nursing human resources must simultaneously consider retention. Professional socialization is recognized as a dynamic process of coming to know a professional role that is influenced by a variety of social experiences over time (Davis 1975). This process holds implications for both career choice (recruitment) and intent to remain (retention) (Day et al. 2005).

The literature on professional socialization and career choice in nursing recognizes that career choice is influenced by past experiences of caregiving, having a family member who is a nurse and a desire to care for others (Larsen et al. 2003; Price 2011). Recent nursing research has also demonstrated that nurses often choose the profession based on preconceived notions of nursing as having job security and flexibility within a variety of settings and locations. Such notions are influenced by media focus on the nursing shortage (Seago 2006). Nurses are also often socialized to perceive nursing as a caring profession. However, recent research demonstrates the dissonance that can occur when new nurses' idealistic perceptions of caring are confronted by concerns of not being able to provide the care required in practice (Mackintosh 2006). Attitudes towards care can move from positive to negative through the career socialization process, which holds implications for job satisfaction and retention (Mackintosh 2006).

To date, much of the nursing literature has focused on understanding why nurses choose the profession, yet understanding perceptions and expectations of profes- 
sional choice can also provide insight into career decision-making, such as intent to remain (Day et al. 2005). There is currently a gap in our understanding of the migration and mobility experiences of Canadian nurses, including the context in which these decisions are made. Understanding professional socialization within migration experiences can provide insight into how to retain nurses within the profession and keep them practising in Canada. Moreover, exploring rationales for migration and mobility among Canadian nurses can provide insight into the early influences on career decisions - information that can be used to develop future recruitment and retention policies and practices (McGillis Hall et al. 2012). This paper will present qualitative findings specific to the role of professional socialization on career decision-making in relation to nurse mobility across the provinces and territories $(\mathrm{P} / \mathrm{T})$ in Canada.

\section{Methods}

A qualitative descriptive design (Sandelowski 2000) was employed to analyze the qualitative comments obtained from a larger survey of registered nurses (RNs) and licensed practical nurses (LPNs) from across Canada focused on nurse migration and mobility (see the paper by McGillis Hall et al. in this Special Issue). Qualitative descriptive designs employ mixed methods for sampling, data collection and analysis in seeking to describe phenomena of interest (Sandelowski 2000). The objective of this analysis is to describe professional socialization factors that influence career decision-making in Canadian nurses.

Thematic analysis (Morse and Field 1995) and a method of constant comparison (Lincoln and Guba 1985) were used to examine relationships and identify emerging themes within the data. Trustworthiness of the findings was established through reflective journaling and investigator triangulation by involving several team members in the analytical process to ensure its accuracy (Lincoln and Guba). Qualitative comments from 152 study participants representing eight different $\mathrm{P} / \mathrm{T}$ form the basis for this analysis. The majority of participants were female (93\%), and close to two-thirds (60\%) were married. Additional demographic details are provided by McGillis Hall and colleagues (2013).

\section{Findings}

The data provided insight into nurses' career choice influences and professional socialization, including their perceptions and expectations of nursing. The findings are presented within two key subthemes that emerged from the analysis: (a) choosing to enter and exit nursing and (b) nursing as a mobile career.

Choosing to enter and exit nursing: Socialized around care The decision to enter nursing was often grounded in the understanding that nursing practice was centred on patient care. Participants described choosing a career in 
nursing specifically for the caring nature of the profession and their desire to work directly with patients. In contrast, others described how the nature of nursing work was taking them away from the bedside, creating a sense of disillusionment with the profession and dissatisfaction with their jobs. Participants identified that the distancing of nursing work from the patient, often towards management, would incite their exploration of other roles, settings and locations, and other careers:

Nursing has gone too far away from the "human" aspect of good patient care and actually caring for people. Due to cutbacks and very negative attitudes, it is becoming [a] very frustrating profession to work in.

Several participants also stated that their commitment to patients provided an incentive to stay in the profession. However, they acknowledged that recent trends in care delivery often force nurses away from the bedside into more administrative positions. Specifically, participants identified that the role of the RN has evolved to include more paperwork and less direct patient contact, a trend that left many nurses dissatisfied with their careers and roles:

Nursing in Canada is turning into paperwork more and more, and patient care is declining because of it. There is very little time during a day for "hands on" with patients. I became a nurse to look after people, not look after "make work" government projects.

I have always loved nursing but lately my feelings are changing due to increased workload. It's like people are not as important as the paperwork. This makes me very sad to see where the nursing career is headed.

Participants described how hospital restructuring, changes in educational preparation and new models of care contributed to the move of RNs away from direct care provision, which was often cited as the main influence in their choice of a nursing career. Several mid- to late career nurses also described how they believed the newest cohort of nursing professionals was "losing touch with bedside nursing" and identified a declining emphasis on caring among new nurses:

I am interested in the calibre of nurses we are now creating. I take in fourthyear nursing students for a work term and I am appalled at their lack of caring and work ethic. What are we teaching our nurses? Nursing used to be a "calling" - now it seems it is just a job to the new nurses. I worry about patient safety and patient care.

The topic of recruitment into the profession was identified, with respondents citing that recent changes in the nature of nursing work make it difficult to encourage that 
career choice among others. Some indicate that if given the chance to go back in time, they would choose a different career; several spoke of how they would not encourage others to follow in their career path, in large part due to challenges in the work environment:

In my job, it's high demands and low on support and respect. This is not a workplace that invites young people in or encourages them to healthy work. I would hate either of my daughters to follow in this path. Life is too short.

\section{Nursing as a mobile career}

Participants often entered the profession with a perception that nursing was a mobile career option. Several described being socialized to view nursing as a career with endless job options, including providing the opportunity for relocation and migration, within and outside Canada. The data revealed an understanding that nurses could work anywhere and that nursing enables variety in both roles and settings:

I've enjoyed moving and seeing other perspectives of nursing in different regions. Some more strict (Ontario), some more laid back (Nova Scotia) and some in midst of transition of [the] healthcare system (Alberta). I've learned different ways of seeing things from different economic and political backgrounds. I enjoy moving and using nursing to facilitate new jobs for my wife and I.

Participants identified several benefits to the mobility associated with being a nurse, including the opportunity for travel. Their relocations had occurred primarily for employment opportunities, personal reasons or both. Proximity to family and social supports were cited as a main influence on migration, and participants described nursing as a career that could support these decisions:

I have found nurses usually will go where there is a full-time job that interests them. If family and friends are there too - then that is where they will settle. I have seen nurses not leave a city and settle for part-time work for years because they do not want to leave family and friends.

Nursing was described as "a career that lends itself to moving around," and the decision to move across $\mathrm{P} / \mathrm{T}$ was often related to spousal employment. The influence of gender within the responses was also evident: given that nursing is largely a female profession, many participants stated that a career as a nurse enabled them to follow their husbands' work opportunities:

Married women quite frequently move because their husbands cannot find work in [a] certain area. Nurses can find work almost anywhere. 
Another related theme was that many nurses relocated in response to having a spouse in the military. Several participants identified that they themselves were military nurses, a fact that also influenced their mobility decisions and reflected their understanding that a nursing career would support relocation. Despite being drawn to nursing because it was a career that enabled mobility and migration, participants also described how the decision to move was not easy:

It is never easy to uproot your life to another location when it is not your choice, but the choice of your spouse when they have the opportunity for a better job.

\section{Discussion}

Choosing to enter and exit nursing: Socialized around care

Canadian nurses in this study described how "caring" and direct patient contact were central to their choice of nursing and career satisfaction. They expressed a desire to work in direct care roles and to maintain the connection with the patient within their practice. Hospital restructuring, changes in educational preparation and new models of care were described as key factors contributing to moving nurses away from direct patient care, which was often cited as the main influence in their choice of a nursing career. The centrality of the concept of caring within the choice of nursing is well recognized in the literature (Mackintosh 2006) and remains key to career choice in new graduates (Price 2011). New nurses often experience a level of cognitive dissonance in relation to having their ideals about nurses and nursing, and patient care, challenged within the "real world" (Day et al. 2005). These findings indicate that the lack of focus on caring within practice causes not only discord but can also lead to nurses' job dissatisfaction and attrition.

Participants in this study identified the need to emphasize the rewards and challenges of a nursing career in the context of the current realities of nursing practice. Recruitment initiatives need to support more realistic perceptions and expectations of nursing given new models of care delivery and evolving scopes of practice (Whitehead et al. 2007). Although these findings are similar to extant research identifying that nurses enter the profession to care for patients, our study provides new insight into how professional socialization experiences can affect job satisfaction, transition and intent to remain within the profession (Peterson et al. 2011).

Nursing as a mobile career choice

In addition to being drawn to the caring aspects of the profession, participants were also socialized to the notion that nursing was a career that enabled mobility. Most of the respondents viewed the opportunity for mobility within nursing as a defining characteristic and positive feature of the profession. Their choice of nursing was informed by the perception that it was a mobile career and that nurses could 
find employment anywhere. Recent research into new graduates' perspectives on a nursing career demonstrate that geographic mobility is an attractive feature of the profession (Gillis et al. 2004), especially among younger, single or childless women (Robinson et al. 2008). Research also demonstrates that the upcoming generations of nurses often choose nursing based on the ability to be mobile within their career (Price 2011).

The opportunity to migrate was cited as beneficial for both personal and professional reasons. Participants identified that proximity to family was an influence on migration intentions, a finding echoed in a recent study of new graduate nurses in Canada (Freeman et al. 2012). The mobility associated with nursing enabled respondents to follow their spouse's careers, especially for military families. Research in gender and career mobility has recognized that professions that facilitate mobile careers, such as nursing, often enable women to follow their husband's work (Bonney 1991). In addition to personal reasons, this study demonstrated that nurses often chose to migrate for professional growth, employment opportunities and career advancement. Participants identified that mobility within nursing could also enhance career development, a finding that echoes recent research into the migration intentions of newly graduated Canadian nurses (Freeman et al. 2012). Understanding that individuals are socialized to view nursing and enter the profession based on opportunities for mobility holds implications for nurse recruitment and retention.

\section{Implications}

This research offers insight into the factors that influence nurses' career decisionmaking. Given that patient care is central to the choice of nursing as a career, this study supports the need for recruitment and socialization initiatives that realistically portray nursing practice within the context of contemporary nursing roles and evolving scopes of practice. Moreover, there is a need for professional nursing organizations, employers and educational institutions to collaborate to ensure adequate recruitment messages and professional socialization. Early socialization strategies such as job-shadowing and student employment programs have been shown to enhance understanding about nurses' roles and increase retention among new graduates (Gamroth et al. 2006). Dissonance and distress during transition to practice are not new phenomena in nursing. However, socialization supports that enhance nurses' understanding of current practice roles, care environments and career development can improve satisfaction and retention within nursing, especially for new graduates (Freeman et al. 2012; Peterson et al. 2011) and upcoming generations of nurses (Price 2009).

The need for policies and practices that support internal migration in the country was also highlighted, as mobility is a key feature of the profession and an incentive 
to choosing nursing as a career. Given the perceptions of nursing as a mobile career, one strategy to retain nurses seeking mobility opportunities may be to highlight inter-P/T nursing positions and for employment and regulatory bodies to support internal migration. Such strategies can ensure that Canadian nurses not only continue to be employed within Canada but also remain within the profession.

\section{Conclusion}

The findings of this qualitative analysis are not intended to show causation or be generalized to other populations. However, this research provides an in-depth, contextualized understanding of the role of professional socialization in career decision-making related to nurse mobility. Through a process of professional socialization, individuals enter a career with perceptions and expectations of what that profession entails. This study demonstrates that early perceptions and expectations of nursing practice can influence nurses' future career decisions, such as mobility and intent to remain. The decision to enter the nursing profession often centres on a desire to provide high-quality care to patients. Evolving scopes of practice and increasing administrative non-direct care activities, which are perceived as incongruent with career expectations, can lead to professional dissatisfaction and attrition. Given the growing complexity of population health needs and the recent emphasis on innovative health human resources management, there is further opportunity to explore how nurses can best contribute to patient care in ways that align with their expectations, interests and expertise. Moreover, with the increasing attention on recruitment and retention to address the growing nursing shortage, there is an opportunity to provide early socialization experiences that more accurately portray the realities and possibilities of contemporary practice.

Nursing is also widely viewed as a career that enables mobility and relocation to accommodate both family considerations and professional development opportunities. Geographic mobility and the opportunity for travel are regarded as attractive features of the nursing profession, especially for younger generations of nurses. Employment agencies and policy leaders must explore ways in which migration between $\mathrm{P} / \mathrm{T}$ can be supported and facilitated as a strategy to enhance retention of nurses within both Canada and the nursing profession.

\section{Acknowledgements}

This study was funded by the Canadian Foundation for Healthcare Improvement and Health Canada's Office of Nursing Policy.

Correspondence may be directed to: Sheri Price, $R N, P h D$, assistant professor, Dalhousie University, School of Nursing, 5869 University Ave., Post Office 15000, Halifax, NS B3H 4R2; tel.: 902-489-8809; fax: 902-494-3487; email:pricesl@dal.ca. 


\section{References}

Bonney, N. 1991. “Gender and Migration: Geographical Mobility and the Wife's Sacrifice.” Sociological Review 39(2): 335-48.

Canadian Nurses Association (CNA). 2009. Tested Solutions for Eliminating Canada's Registered Nurse Shortage. Ottawa: Author.

Davis, F. 1975. "Professional Socialisation as Subjective Experience: The Process of Doctrinal Conversion among Student Nurses.” In C. Cox \& A. Mead (Eds.), A Sociology of Medical Practice (pp. 116-131). London: Collier McMillan.

Day, R., P. Field, I. Campbell and L. Reutter. 2005. “Students' Evolving Beliefs about Nursing: From Entry to Graduation in a Four-Year Baccalaureate Programmer." Nurse Education Today 25(5): 636-43.

Freeman, M., A. Baumann, N. Akhtar-Danesh, J. Blythe and A. Fisher. 2012. "Employment Goals, Expectations and Migration Intentions of Nurse Graduates in a Canadian Border City: A Mixed Methods Study." International Journal of Nursing Studies. Retrieved December 31, 2012. doi: 10.1016/j.injurstu.2012.07.015.

Gamroth, L., C. Budgen and M. Lougheed. 2006. "Feasibility and Outcomes of Paid Undergraduate Student Nurse Positions." Canadian Journal of Nursing Leadership 19(3): 1-14.

Gillis, A., W. Jackson and D. Beiswanger. 2004. "University Nurse Graduates: Perspectives on Factors of Retention and Mobility." Canadian Journal of Nursing Leadership 17(1): 97-110.

Larsen, P., J. McGill and S. Palmer. 2003. "Factors Influencing Career Decisions: Perspectives of Nursing Students in Three Types of Programs." Journal of Nursing Education 42(4): 168-73.

Lincoln, Y. and E. Guba. 1985. Naturalistic Inquiry. London, UK: Sage Publications.

Mackintosh, C. 2006. “Caring: The Socialization of Pre-Registration Student Nurses: A Longitudinal Qualitative Descriptive Study.” International Journal of Nursing Studies 43(8): 953-62.

McGillis Hall, L., J. Peterson, S. Price, G. Andrews, M. Lalonde, A. Harris et al. 2013. "I Was Never Recruited: Challenges in Cross-Canada Nurse Mobility." Canadian Journal of Nursing Leadership 28(Special Issue): 29-40.

McGillis Hall, L., J. Peterson, S. Price, G. Andrews, M. Lalonde, S. Johnson et al. 2012. Moving to Action: Evidence-Based Retention and Recruitment Policy Initiatives for Nursing. Ottawa: Canadian Health Services Research Foundation.

Morse, J. and P. Field. 1995. Qualitative Research Methods for Health Professionals (2nd ed.). Thousand Oaks, CA: Sage Publications.

Peterson, J., L. McGillis Hall, L. O’Brien-Pallas and R. Cockerill. 2011. “Job Satisfaction and Intentions to Leave in New Nurses.” Journal of Research in Nursing 16(6): 536-48.

Price, S. 2009. "Becoming a Nurse: A Review and Synthesis of Qualitative Research on Socialization to the Nursing Profession." Journal of Advanced Nursing 65(1): 11-19.

Price, S. 2011. The Experience of Choosing Nursing as a Career: Narratives from Millennial Nurses. Unpublished doctoral dissertation, University of Toronto.

Robinson, S., T. Murrells and P. Griffiths. 2008. "Investigating the Dynamics of Nurse Migration in Early Career: A Longitudinal Questionnaire Survey of Variation in Regional Retention of Diploma Qualifiers in England.” International Journal of Nursing Studies 45(7): 1064-80.

Sandelowski, M. 2000. "Whatever Happened to Qualitative Description?" Research in Nursing and Health 23(4): 334-40.

Seago, J. 2006. “The Nursing Shortage: Is It Really about Image?” Journal of Healthcare Management 51(2): 96-108.

Whitehead, E., T. Mason and J. Ellis. 2007. “The Future of Nursing: Career Choices in Potential Student Nurses." British Journal of Nursing 16(8): 491-96.

World Health Organization (WHO). 2006. Working Together for Health: The World Health Report 2006. Geneva: Author. 